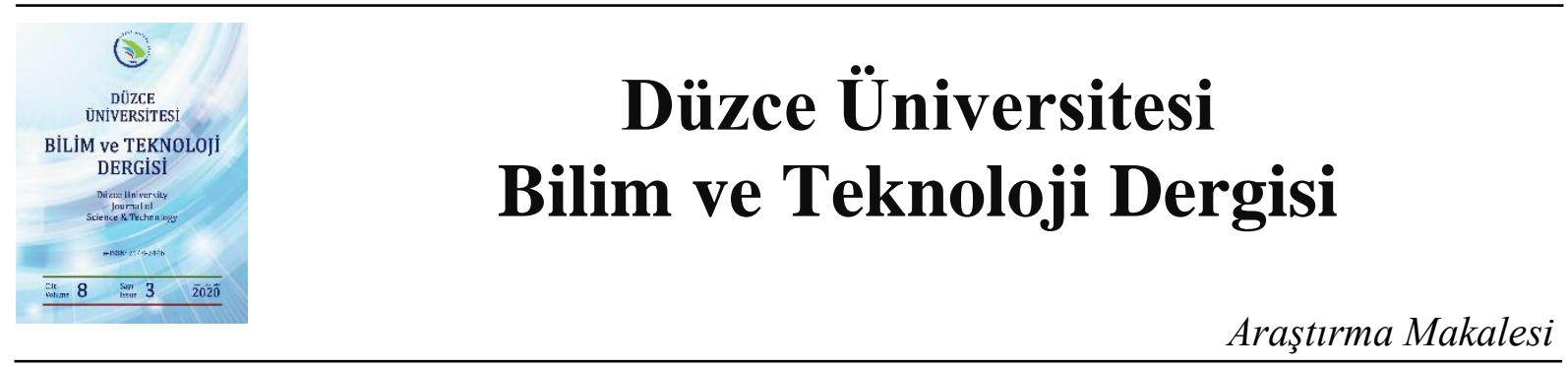

\section{Zamanla Değişken Kütleye Sahip Kütle Yay Sönüm Sisteminin Periyodik Olmayan Titreşimleri}

\author{
Dözde SARI a ${ }^{\text {** }}$, (D) Yasemin Nur AYDIN a \\ ${ }^{a}$ Makine Mühendisliği Bölümü, Mühendislik Fakültesi, Manisa Celal Bayar Üniversitesi, 45140, Manisa, \\ TÜRKIYE \\ * Sorumlu yazartn e-posta adresi: gozde.deger@cbu.edu.tr
} DOI: 10.29130/dubited.670658

\begin{abstract}
ÖZET
$\mathrm{Bu}$ çalı̧̧mada zamana bağlı üstel fonksiyon ile değişken kütleli, sönümlü, tek serbestlik dereceli sistemin titreşimleri araştııılmıştır. Literatürde sunulan birçok çalışma değişken kütleli sistemlerde reaktif kuvvetin dikkate alınması gerektiğini belirtmektedir. Bu nedenle sistemin matematiksel modelinde sistemden ayrılan/eklenen kütle hızı ile sistem hızı arasındaki farkın etkisinden dolayı meydana gelen reaktif kuvvet dikkate alınmıştır. İkinci mertebe adi diferansiyel denklemin çözümü çok ölçekli metot ile elde edilmiştir. Sistemin çözümü periyodik titreşime göre farklılık göstermektedir. Kütlenin zamanla değişmesi, sistemin periyodik olmayan titreşim yapmasına neden olmaktadır. Sistemin genliği ve frekansı zamana bağlı olarak değişmektedir. Sistemin genliği sönüm ve reaktif kuvvet parametrelerine bağlı olarak değişmektedir. Reaktif kuvvet dikkate alınmadığında sistemin kütlesi arttı̆̆ında veya azaldığında sistemin genliği, sönüm etkisi ile zamanla azalmaktadır. Reaktif kuvvet dikkate alındığında ise, kütle zamanla arttığında reaktif kuvvet ile sönüm kuvveti etkisi ile sistemin genliği azalmaktadır. Kütlenin azaldığı durumda reaktif kuvvet sistemin genliğini arttırırken, sönüm kuvveti sistemin genliğini azaltmaktadır.
\end{abstract}

Anahtar Kelimeler: Değişken Kütleli Sistem, Serbest Titreşim, Çok Ölçekli Metot, Periyodik Olmayan Titreşimler, Sönümlü Titreşim

\section{Nonstationary Vibrations of Time-varying Mass Oscillators}

\section{ABSTRACT}

In this study, free vibration of a single-degree-of-freedom system which had a time-varying mass, a damper was investigated. Many studies in the literature state that reactive force should be taken into account in variable mass systems. Therefore the reactive force due to the effect of the difference between the mass speed separated / added from the system and the system speed was taken into account in the mathematical model of the system. The solution of the second-order ordinary differential equation was obtained by the multi-scale method. The solution of the system changed according to periodic vibration. The change of mass with respect to time caused the system to vibrate non-periodically. The amplitude and frequency of the system varied with respect to time. The amplitude of the system varied depending on the damping and reactive force parameters. When the reactive force was not taken into account, whether the mass of the system increases or decreases, the amplitude of the system decreases with respect to time with the damping effect. When the reactive force is taken into account, when the mass increases with respect to time, the amplitude of the system decreases with the effect of reactive force and damping 
force. When the mass decreases, the reactive force increases the amplitudes of the system while the damping force decreases the amplitudes.

Keywords: Variable Mass System, Free Vibration, Multiple Scales Method, Nonstationary Vibrations, Damped Vibration

\section{GIRIS}

Değişken kütleli sistem problemi 17. Yüzyıldan beri incelenmektedir. Mühendislik ve astronomi literatüründe kütle değişimini inceleyen birçok çalışma bulunmaktadır. Bu çalışmalar; uçaklar, roketler, otomobiller, taşıma makineleri, konveyörler, santrifüj dekantörler gibi birçok makineyi kapsar. $\mathrm{Bu}$ mekanizmalarda elemanların kütlesi değiştiğinde kütle merkezinin yeri ve atalet momenti değişim gösterir [1],[2]. Bu durum makine elemanlarında genlik ve doğal frekans değerinin değişmesine, hatta bazı durumlarda dengesiz dinamik harekete sebep olabilir [3]. Literatürde yapılan bazı örnek çalışmalar şöyledir: Abramian vd. [4] çalışmalarında değişken kütleli Euler-Bernoulli kiriş modelinin, kararlılık problemine çözüm olacak yeni bir asimptotik metot ortaya koymuşlardır. Cveticanin [5] çalışmasında nonlineer modellenmiş rotor titreşimlerini incelemiştir. Değişken kütleli sistemin sönüm etkisi ile genlik frekans bağıntıları elde edilmiştir. Terumichi vd. [6] çalışmalarında zamanla uzunluğu değişken sicimin zorlamalı titreşimlerini incelemişlerdir. Sistem iki serbestlik derecesine sahiptir. Analitik olarak, sicimin eksenel hızı rezonans geçişi sırasında, sicim uzunluğuna bağlı olarak değişmektedir. Teorik sonuçlar basit deney düzeyi ile deneysel olarak onaylanmıştır. Cveticanin vd. [7] çalışmalarında değişken kütleli rotor/akışkan sisteminin kararlı dönüşündeki sınırları saptamışlardır. Direk Lyapunov metodu kararlılık analizi için uygulanmış, ikinci mertebe diferansiyel denkleme sönüm ve yavaş zaman terimleri de eklenerek Krylov-Bogolubov metodu ile analitik kararsızlık tanımlanmıştır. Holl vd. [8] çalışmalarında zamana göre değiş̧ken kütleli osilatörü temsil eden bir model ele almışlardır. Osilatörün titreşimleri için analitik bir çözüm sunulmuştur. Üstel veya sinüzoidal olarak değişken kütleye sahip sistemin titreşimleri elde edilmiştir. Flores vd. [9] çalışmalarında değişken kütleli osilatörün hareketini incelemişlerdir. Osilatörün zamana bağlı kütle değişimi modellenerek kesin çözüm elde edilmiştir. Burgh vd. [10] çalışmalarında yağmur ve rüzgar etkilerinin osilatör üzerindeki etkisini belirleyebilmek için değişken kütleli tek serbestlik dereceli matematiksel bir model önermişlerdir. Yağmur damlalarının sistem titreşimlerine etkileri araştırılmıştır. Horssen [11] çalışmalarında, sönümlü, tek serbestlik dereceli sistemin titreşimlerini ele almışlardır. Sistemin kütlesi zamanla değişmektedir. Sistemin zorlamalı ve zorlamasız titreşimleri incelenmiştir. Sistemin serbest titreşimlerde osilatörün her zaman kararlı olduğu normal sönüm oranları hesaplanmıştır. Zhu ve Wang [12] çalışmalarında, zamanla değişken kütleye sahip sistemin lineer titreşimlerini incelemişlerdir. Kütle değişimi sinüzoidaldir. Parametrik olarak zorlanan sistemin davranışı deplasman zaman grafikleri ile sunulmuştur. Zukovic ve Kovacic [13] çalışmalarında döngüsel olarak tanımlanmış kütle değişimi içeren osilatörün serbest titreşim davranışını incelemişlerdir. Kütle değişimi iki farklı fonksiyon olarak tanımlanmıştır. Birincisinde, kütle zamanla doğrusal olarak artar ve azalır yani üçgen şeklinde değişir. İkincisinde ise kütle yamuk şeklinde değişir. Her bir fonksiyon için kesin çözümler ve kararlılık kriterleri elde edilmiştir. Horssen vd. [14] çalışmalarında osilatörden ayrılan küçük kütlelerin sistemin davranışına etkisini incelemişlerdir. Dikkate alınan sistem, tek serbestlik dereceli, zamana bağlı değişken parametreli ve zorlamalı olarak modellenmiştir. Ji-Hu vd. [15] çalışmalarında Hamilton prensibi yardımıyla zamana bağlı değişkenlik gösteren halat çekme ipinin titreşimini modellemişlerdir. Geliştirilen matematiksel model, asansör halat sistemi üzerinde kullanılarak esnek çekme sistemlerinde aktif olarak kullanılabileceği sonucuna varılmıştır. Horssen vd. [16] çalışmalarında tek serbestlik dereceli osilatörün değişken kütleli serbest titreşimlerini modelleyip farklı parametreler için kararlılık diyagramlarını incelemişlerdir. Pischanskyy vd.[17] çalışmalarında zamanla değişen bir kütleye sahip, sönümsüz, tek serbestlik dereceli bir osilatörün zorlanmış titreşimlerini lineer olmayan bir şekilde yarı analitik perturbasyon metodunu uygulayarak ifade etmişlerdir.

Bu çalışmada zamana göre sürekli değişken kütleli osilatörü temsilen bir model ele alınmıştır. Modelde kütle üstel olarak değişmektedir. Kütle değişimi yavaşça olmaktadır. Osilatörün titreşimleri için analitik bir çözüm elde edilmiştir. Matematiksel modelde dikkate alınan reaktif kuvvetin sistemin deplasman 
genliğine etkisi ortaya konmuştur. Ayrıca sönüm parametresinin farklı değerleri için çizdirilen grafikler sönümün sistem genlikleri üzerine etkisini göstermiştir. Bu çalışmanın literatüre katkısı reaktif kuvvet ve sönüm kuvvetinin, üstel fonksiyon ile ifade edilerek değişken kütleli sistemin davranışı üzerindeki etkilerinin belirlenmesidir.

\section{DEĞİSKEN KÜTLELİ KÜTLE YAY SÖNÜM SISTEMININ TEORIKK OLARAK MODELLENMESI}

\section{A. HAREKET DENKLEMI}

$\mathrm{Bu}$ bölümde değişken kütleye sahip sistemin serbest titreşimleri teorik olarak modellenmekte ve çözülmektedir. Değişken kütleli sistemin şematik modeli Şekil 1'de görülmektedir.

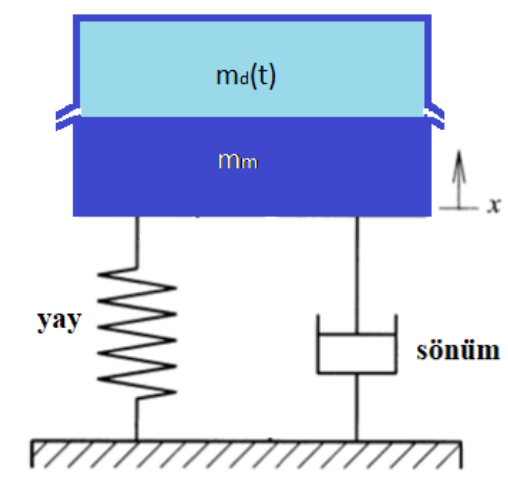

Şekil 1. Değişken kütleli sistemin matematiksel modeli

Değişken kütleli sistem; fonksiyona bağlı değişken kütle, yay ve sönümden oluşmaktadır. Değişken kütleli sistemde sistemden ayrılan veya sisteme eklenen kütlenin hızının da dikkate alındığı model Irschik ve Holl [18] tarafından önerilmiştir. Modelde sistemden kütle ayrıldığında veya eklendiğinde osilatör kütlesinin merkez pozisyonunun değişmediği varsayılmıştır. Tek serbestlik dereceli sistemin titreşimlerini ifade eden diferansiyel denklem aşağıda verilmiştir:

$m^{*}\left(t^{*}\right) \frac{d^{2} x^{*}}{d t^{* 2}}+c \frac{d x^{*}}{d t^{*}}+k x^{*}=\frac{d m^{*}}{d t^{*}}\left(u^{*}-\frac{d x^{*}}{d t^{*}}\right)$

Denklemde; $\mathrm{m}^{*}\left(\mathrm{t}^{*}\right)$ (zamana bağlı değişken kütle), c (sönüm katsayısı), k (lineer yay katsayısı), $\mathrm{t}^{*}$ (boyutlu zaman), $x^{*}$ (boyutlu deplasman fonksiyonu), $u^{*}$ (azalan/artan kütle hızı)'dır. Denklem (1)'deki eşitliğin sağ tarafındaki terim eklenen/ayrılan kütlenin hızından kaynaklanan reaktif kuvvettir. Öncelikle $m^{*}\left(t^{*}\right)$ (zamana bağlı değişken kütle), $m_{m}$ (sabit kütle ) ve $m_{d}^{*}\left(t^{*}\right)$ (zamana bağlı değişken kütle)'nin toplamı şeklinde ifade edilir:

$m^{*}\left(t^{*}\right)=m_{m}+m_{d}^{*}\left(t^{*}\right)$

$m_{d}^{*}\left(t^{*}\right)=m_{d} m_{d}^{*}\left(t^{*}\right)$

Boyutsuzlaştırma işleminin gerçekleşmesi için $\mathrm{t}^{*}$ (boyutlu zaman), $\mathrm{x}^{*}$ (boyutlu deplasman fonksiyonu), $u^{*}$ (azalan/artan kütle hızı)'nın eşitlikleri yazılır:

$x=\frac{x^{*}}{x_{o}} \quad, \quad t=\frac{t^{*}}{T_{o}} \quad, \quad u=\frac{u^{*}}{u_{o}}$ 
Genel sonuçlar elde etmek için Denklem 1 boyutsuzlaştırılır. Denklem mm’e bölünür.

$\mathrm{m}\left(t T_{0}\right) \frac{d^{2} x}{d t^{2}}+\frac{\dot{\mathrm{m}}(\mathrm{t})}{m_{m}} \frac{d x}{d t}+\mu \omega_{0} \frac{d x}{d t}+\omega_{0}^{2} x=0$

Burada $m\left(t T_{0}\right)=1+m_{r}\left(t T_{0}\right), \mu=\frac{c}{\sqrt{k m_{m}}}$ ve $\mathrm{m}_{\mathrm{r}}=\mathrm{m}_{\mathrm{d}} / \mathrm{m}_{\mathrm{m}}{ }^{\prime}$ dir. $(\mathrm{u}(\mathrm{t})=0$ için $)$

$\mathrm{T}_{0}$ (diferansiyel denklemin zaman ölçeği) aşağıdaki gibi belirlenebilir:

$\frac{k T_{0}^{2}}{m}=\omega_{0}^{2} \quad$ olarak seçilirse,

$\mathrm{T}_{0}=\omega_{0} \sqrt{\frac{m}{k}} \quad$ olarak elde edilir.

Denklem (5) $\frac{1}{m(t)}$ ile çarpılırsa;

$\frac{d^{2} x}{d t^{2}}+\frac{\dot{\mathrm{m}}(\mathrm{t})}{\mathrm{m}(\mathrm{t})} \frac{d x}{d t}+\frac{\mu \omega_{0}}{m(t)} \frac{d x}{d t}+\frac{\omega_{0}^{2} x}{m(t)}=0$

elde edilir. Burada $\frac{\mathrm{m}^{*}(t)}{m_{m}}=\dot{m}(\mathrm{t})^{\prime}$ dir.

$\frac{\dot{m}}{\mathrm{~m}}=-\frac{2 \dot{\omega}}{\omega}$ eşitliği Denklem (8)'de yerine yazılırsa,

$\frac{d^{2} x}{d t^{2}}+\frac{\mu \omega_{0}}{m(t)} \frac{d x}{d t}-2 \frac{\dot{\omega}(\mathrm{t})}{\omega(t)} \frac{d x}{d t}+\frac{\omega_{0}^{2} x}{m(t)}=0$

elde edilir. Değişken kütleli sistemin serbest titreşimlerini veren boyutsuz diferansiyel denklem

$\frac{d^{2} x}{d t^{2}}+\left(h_{1}(t)+h_{2}(t)\right) \frac{d x}{d t}+\omega(t)^{2} x=0$

şeklindedir. Burada $\omega(\mathrm{t})=\frac{\omega_{0}}{\sqrt{\mathrm{m}(\mathrm{t})}}$ (zamana bağl1 tabi frekans) şeklindedir.

Ayrıca $h_{1}(t)=\frac{\mu \omega_{0}}{m(t)}$ (sönüm ile ilgili değişken katsayı) ve $h_{2}(t)=-\frac{2 \omega(t)}{\omega(t)} \quad$ (reaktif kuvvet ile ilgili değişken katsayı) şeklindedir. Bundan sonraki işlemler için $h(t)=h_{1}(t)+h_{2}(t)$ olarak tanımlanacaktır.

\section{B. PERTURBASYON ANALIZI}

Yavaşça değişken kütleye sahip olan sistemin boyutsuz hareket denklemi perturbasyon metodu olan çok ölçekli metot uygulanarak çözülmektedir. Burada $\tau=\varepsilon t$ ve $\varepsilon$ küçük ve boyutsuz parametredir. $\varepsilon$ küçük olduğu için $\tau$ yavaş zaman ölçeğidir. $\frac{d \emptyset}{d t}=\omega(\tau)$ şeklindedir. Bu çözüm için zaman, $\tau$ ve $\varnothing$ değişkenleri ile ölçeklendirilmektedir [19], [20], [21]. Bu değişkenler ile yazılmış zaman türev ifadeleri aşağıdaki gibidir:

$$
\begin{aligned}
& \frac{d}{d t}=\omega \frac{d}{d \emptyset}+\varepsilon \frac{d}{d \tau} \\
& \frac{d^{2}}{d t^{2}}=\omega \frac{d^{2}}{d \emptyset^{2}}+\varepsilon\left(2 \omega \frac{d^{2}}{d \tau d \emptyset}+\dot{\omega} \frac{d}{d \varnothing}\right)+\varepsilon^{2} \frac{d^{2}}{d \emptyset^{2}}
\end{aligned}
$$


Sistemin çözümü aşağıdaki gibi önerilmiştir:

$x(t, \varepsilon)=x_{0}(\varnothing, \tau)+\varepsilon x_{1}(\varnothing, \tau)$

Sistemin kütle değişiminin yavaş zaman ölçeğinde olduğu kabul edilmiştir. Bu nedenle h fonksiyonu $\varepsilon t^{\prime} y e$ bağlıdır ve $h(\varepsilon t)=h(\tau)$ şeklindedir. Sistem az sönümlü ve kütle oranı $\mathrm{m}_{\mathrm{r}}$ küçük alınırsa sönüm ve zamana bağlı kütle ve frekans ifadelerini içeren $h(\tau)$ ifadesi de $\mathrm{h}(\tau)=\varepsilon \overline{\mathrm{h}(\tau)}$ olarak ölçeklenir. $\mathrm{Bu}$ eşitlik, Denklem (10)'da yerine yazılır ve her bir $\varepsilon$ mertebesinde aşağıdaki denklemler elde edilir. Önerilen denklem 1 mertebesi ve $\varepsilon$ mertebesi eşitliklerine ayrıştırılır:

$O(1): \omega^{2}\left(\frac{d^{2} x_{0}}{d \emptyset^{2}}+x_{0}\right)=0$

$O(\varepsilon): \omega^{2}\left(\frac{d^{2} x_{1}}{d \emptyset^{2}}+x_{1}\right)=-2 \omega \frac{d^{2} x_{0}}{d \tau d \varnothing}-\omega^{\prime} \frac{d x_{0}}{d \varnothing}-h(\tau) \omega \frac{d x_{0}}{d \varnothing}$

1 mertebesi için oluşturulan $\mathrm{O}(1)$ çözümü kompleks formda aşağıdaki gibidir:

$x_{0}=A(\tau) e^{i \varnothing}+\bar{A}(\tau) e^{-i \varnothing}$

Seküler terimler ayrıştırılıp 0’a eşitlenir:

$e^{i \emptyset}\left(-2 \omega A^{\prime} i-\omega^{\prime} A i-h \omega A i\right)=0$

Kompleks genlik tanımı polar formda yazılır:

$A=\frac{1}{2} a e^{i \beta}$

Denklem (16), Denklem (15)’te yerine yazılır ve gerçek-sanal kısımlarına ayrılırsa,

$$
\begin{gathered}
\text { Sanal: } a^{\prime}=-\frac{1}{2} \frac{\omega \prime}{\omega} a-\frac{1}{2} h a=0 \\
\text { Reel: } \beta^{\prime}=0
\end{gathered}
$$

Denklem (17)'den genlik ve faz fonksiyonları elde edilir ve Denklem (14)'ün içine yazılırsa

$$
x(\tau)=a \cos \left(\varnothing+\beta_{0}\right)+O(\varepsilon) \quad \mathrm{a}=c_{1} e^{\int\left(-\frac{\dot{\omega}}{2 \omega}-\frac{h}{2}\right) d \tau}
$$

elde edilir. Başlangıç şartları $x(0)=1$ ve $\dot{x}(0)=0$ alınır ve Denklem(18)'de $\tau=\varepsilon$ t ve $\emptyset=\omega$ t yerine yazilırsa,

$\mathrm{h}_{1}=0$ ve $m=1+m_{r} e^{\varepsilon t}$ kütle değişim fonksiyonu için;

$\mathrm{x}(\mathrm{t})=\frac{e^{\log \left(m_{r} e^{\tau}+1\right)\left(\frac{\mu \omega_{0}}{2}+\frac{1}{4}\right)-\frac{\tau \mu \omega_{0}}{2}}}{e^{\log \left(m_{r}+1\right)\left(\frac{\mu \omega_{0}}{2}-\frac{1}{4}\right)}} \cos (\omega \mathrm{t})$

elde edilir. h=0 ve $m=1+m_{r} e^{-\varepsilon t}$ kütle değişim fonksiyonu için;

$\mathrm{x}(\mathrm{t})=\frac{e^{-\log \left(m_{r} e^{-\tau}+1\right)\left(\frac{\mu \omega_{0}}{2}-\frac{1}{4}\right)-\frac{\tau \mu \omega_{0}}{2}}}{e^{-\log \left(m_{r}+1\right)\left(\frac{\mu \omega_{0}}{2}-\frac{1}{4}\right)}} \cos (\omega \mathrm{t})$

elde edilir. $h \neq 0$ ve $m=1+m_{r} e^{\varepsilon t}$ kütle değişim fonksiyonu için; 
$\mathrm{x}(\mathrm{t})=\frac{e^{\log \left(m_{r} e^{\tau}+1\right)\left(\frac{\mu \omega_{0}}{2}-\frac{1}{4}\right)-\frac{\tau \mu \omega_{0}}{2}}}{e^{\log \left(m_{r}+1\right)\left(\frac{\mu \omega_{0}}{2}-\frac{1}{4}\right)}} \cos (\omega \mathrm{t})$

elde edilir. $h \neq 0$ ve $m=1+m_{r} e^{-\varepsilon t}$ kütle değişim fonksiyonu için;

$\mathrm{x}(\mathrm{t})=\frac{e^{-\log \left(m_{r} e^{-\tau}+1\right)\left(\frac{\mu \omega_{0}}{2}+\frac{1}{4}\right)-\frac{\tau \mu \omega_{0}}{2}}}{e^{-\log \left(m_{r}+1\right)\left(\frac{\mu \omega_{0}}{2}+\frac{1}{4}\right)}} \cos (\omega \mathrm{t})$

elde edilir. Sistemin davranışı, tabi frekans değerlerine göre değişmektedir. Ayrıca sistemin cevabı kütlenin değişimini ifade eden denklemin özelliği ile de direkt ilgilidir. Denklem (19)-(22)'de elde edilen çözümler çalışmamızda belirtilen özel kütle değişim fonksiyonu için elde edilmiştir. Sonuçlar bölümde bu özel fonksiyonun sistem cevabına etkisi sunulmaktadır.

\section{LITERATÜR İLE KARŞILAŞTIRMA}

Değişken parametreli dinamik sistemlerin çözümü için çok ölçekli metot kullanımı önerisi ilk kez Nayfeh vd. tarafından 1995 yılında yapılmıştır (Nayfeh vd. [20]). Değişken kütleye sahip sistemlerin dinamik davranışları analitik olarak birçok çalışmada incelenmiştir (Cveticanin [5], Terumichi vd. [6], Horssen ve Pischanskyy [11], Zhu ve Wang [12], Pischanskyy ve Horssen [17], Abramian vd. [4]).

Bu çalışmada, kütle değişimi üstel bir fonksiyonla ifade edilmiştir ve problemin çözümü çok ölçekli metot ile elde edilmiştir. Sistemin deplasman genliği çözümü bir önceki bölümde Denklem 18'de yazılmıştır. Bu çözümün literatürle uyumunu göstermek üzere Cveticanin'in 2016'da yazmış olduğu kitaptan faydalanılmıştır (Cveticanin [1]). Bu kitaptan örnek olarak alınan problem:

$\frac{d^{2} x}{d t^{2}}+\frac{\dot{m}}{m} \frac{d x}{d t}+\omega(t)^{2} x=0$

şeklindedir. Değişken kütle fonksiyonu $\mathrm{m}=\left(\mathrm{m}_{0}+\varepsilon t\right)^{2}$ için sistemin genlik çözümleri ve sonuçları literatürle Tablo 1'de karşılaştırılmıştır.

Tablo 1. Literatür karşılaştırması için ele alınan örnek problemin sistem genliği çözümü ve sonucu

\begin{tabular}{lccc}
\hline & $\begin{array}{c}\text { Sistem Genliği } \\
\text { Çözümü }\end{array}$ & Sistem Genliği Sonucu & Sistemin Deplasman Sonucu \\
\hline $\begin{array}{l}\text { Mevcut } \\
\text { çalışma }\end{array}$ & $\mathrm{a}=c_{1} e^{\int\left(-\frac{\dot{\omega}}{2 \omega}-\frac{h}{2}\right) d \tau}$ & $\mu=0, \mathrm{~h}=\frac{\dot{m}}{m}$ ve $\omega=\frac{1}{\sqrt{\mathrm{m}}} \mathrm{için}$ & $\mathrm{x}(\mathrm{t})=\left((\varepsilon \mathrm{t}+1)^{2}\right)^{1 / 4} \cos (\omega \mathrm{t})$ \\
$\begin{array}{l}\text { Literatür } \\
\text { (Cveticanin }\end{array}$ & $\mathrm{a}=c_{1}\left(\frac{m_{0}}{m}\right)^{1 / 4}$ & $\mathrm{~m}_{0}=1$ için & $\mathrm{x}(\mathrm{t})=\left((\varepsilon \mathrm{t}+1)^{2}\right)^{1 / 4} \cos (\omega \mathrm{t})$ \\
[1]) & $\mathrm{a}=\left((\varepsilon \mathrm{t}+1)^{2}\right)^{1 / 4}$ & \\
\hline
\end{tabular}

Tablo 1'de bu çalışmada elde edilen sistem genliği ve deplasman sonucu ile literatür sonucunun aynı olduğu görülmektedir. Böylelikle çalışmamızda sunulan çözümlerin doğruluğu literatürden alınan bir örnek karşılaştırma ile gösterilmiştir.

\section{III.BULGULAR VE TARTISMA}

İkinci bölümde elde edilen değişken kütleli sistemin zamana bağlı deplasman çözümleri bu bölümde grafikler ile gösterilecektir. Çözümler incelendiğinde genlik ve frekansın zamana bağlı olduğu görülmektedir. Reaktif kuvvetin dikkate alındığı ve alınmadığı durumlar için grafikler elde edilmektedir. 
Şekil 2-5'te zamanla değişken kütleye sahip sistemlerin genlik zaman grafikleri görülmektedir. Şekil 2'de zamanla artan kütleye sahip sistemin farklı sönüm değerleri için genlik zaman grafikleri çizdirilmiştir. Reaktif kuvvet dikkate alınmamıştır. Sönümün olmadığı durum incelenirse kütle arttıkça genlik artmaktadır. Sönümün küçük değerleri için genlik belirli bir zamana kadar azalmaktadır, sonrasında genlik artmaktadır. Sönüm değerinin yeterince büyük değerlerinde ise genlik zamanla sürekli azalmaktadır. Şekil 3'te genlik zaman grafiği azalan kütleye sahip sistem için çizdirilmiştir. Reaktif kuvvet dikkate alınmamıştır. Sönümün olmadığı durum incelendiğinde sistemin kütlesi azaldıkça genlik değerleri de azalmaktadır. Sönüm değeri arttıkça genlik değerleri daha hızlı azalmaktadır. Şekil 4'te reaktif kuvvet dikkate alınarak artan kütleye sahip sistemin genlik zaman grafiği elde edilmiştir. Sönüm değeri sıfır alındığı duruma bakıldığında zamanla artan kütleye sahip sistemin genlik değerleri azalmaktadır. Sönüm değerleri arttııldığında genlik zamanla daha hızlı azalmaktadır. Şekil 5'te reaktif kuvvet dikkate alınarak azalan kütleli sistemin genlik zaman grafiği çizdirilmiş̧ir. Sönüm değeri sıfir alındığında sistemin genliği zamanla artmaktadır. Sisteme sönüm eklendiğinde sistemin genlikleri azalmaktadır. Sönümün küçük değerlerinde genlikler önce artmakta sonrasında azalmaktadır. Sönümün yeterince büyük değerlerinde ise sistemin genliği hiç artı̧̧ göstermeden direkt azalmaktadır. Tablo 2'de reaktif kuvvetin etkisini açıkça gösterebilmek için, sistemin reaktif kuvvete bağlı değişen deplasman genliği sonuçları sayısal olarak gösterilmiştir. Böylelikle reaktif kuvvet etkisinin dikkate alındığı durumda; kütle zamanla arttıkça deplasman genliklerinin zamanla azalması, kütle zamanla azaldıkça deplasman genliklerinin zamanla artması sayısal verilerle gösterilmiştir. Sonuç olarak kütlenin değişkenlik gösterdiği sistemlerde reaktif kuvvetin etkisinin önemi sayısal olarak ifade edilmiştir.

Şekil 6-9'da zamanla değişken kütleli sistemlerin deplasman zaman grafikleri görülmektedir. Şekil 6 ve 7'de reaktif kuvvet dikkate alınmamıştır. Şekil 6'da zamanla artan kütleye sahip kütle yay sönüm sisteminin boyutsuz sönüm katsayısı $\mu=0.2$ için deplasman zaman grafiği çizdirilmiştir. Deplasman ve doğal frekans değerleri zamanla azalmaktadır. Şekil 7'de zamanla azalan kütleye sahip sistemin boyutsuz sönüm katsayısı $\mu=0.2$ için deplasman zaman grafiği elde edilmiştir. Deplasman zamanla azalmakta, doğal frekans ise zamanla artmaktadır. Şekil 8 ve 9'da reaktif kuvvet dikkate alınmıştır. Şekil 8 'de zamanla artan kütleye sahip sistemin boyutsuz sönüm katsayısı $\mu=0.2$ için deplasman zaman grafiği elde edilmiş̧ir. Sistemin deplasmanı ve doğal frekansı zamanla azalmaktadır. Şekil 9'da zamanla azalan kütleye sahip sistemin boyutsuz sönüm katsayısı $\mu=0.02$ için deplasman zaman grafiği elde edilmiştir. Sistemin doğal frekansı artmaktadır. Deplasman değerleri ise kütle değişimi nedeniyle önce artmakta, belirli bir zamandan sonra sönüm etkisi ile azalmaktadır.

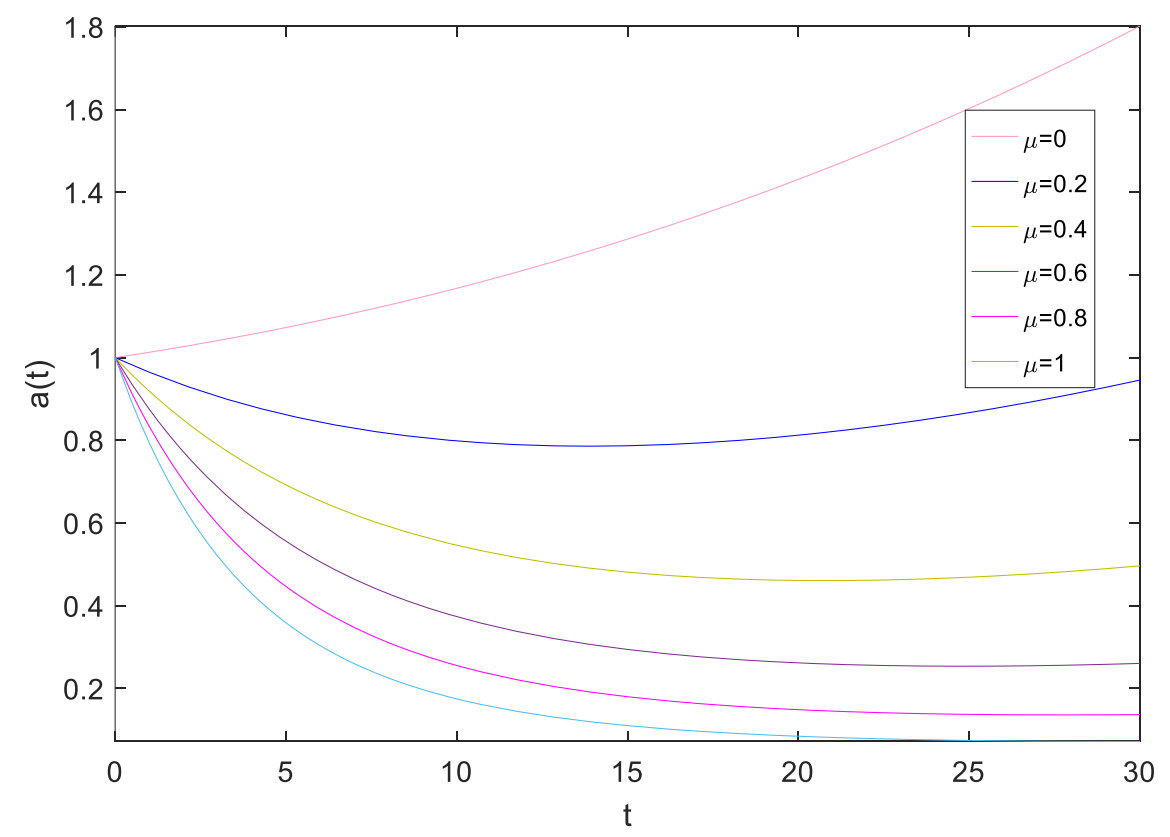

Şekil 2. Zamanla artan kütleye sahip kütle yay sönüm sisteminin deplasman genliği-zaman grafiği $\left(h_{2}=0, \omega_{0}=10, m_{r}=1, \varepsilon=0.1\right)$ 


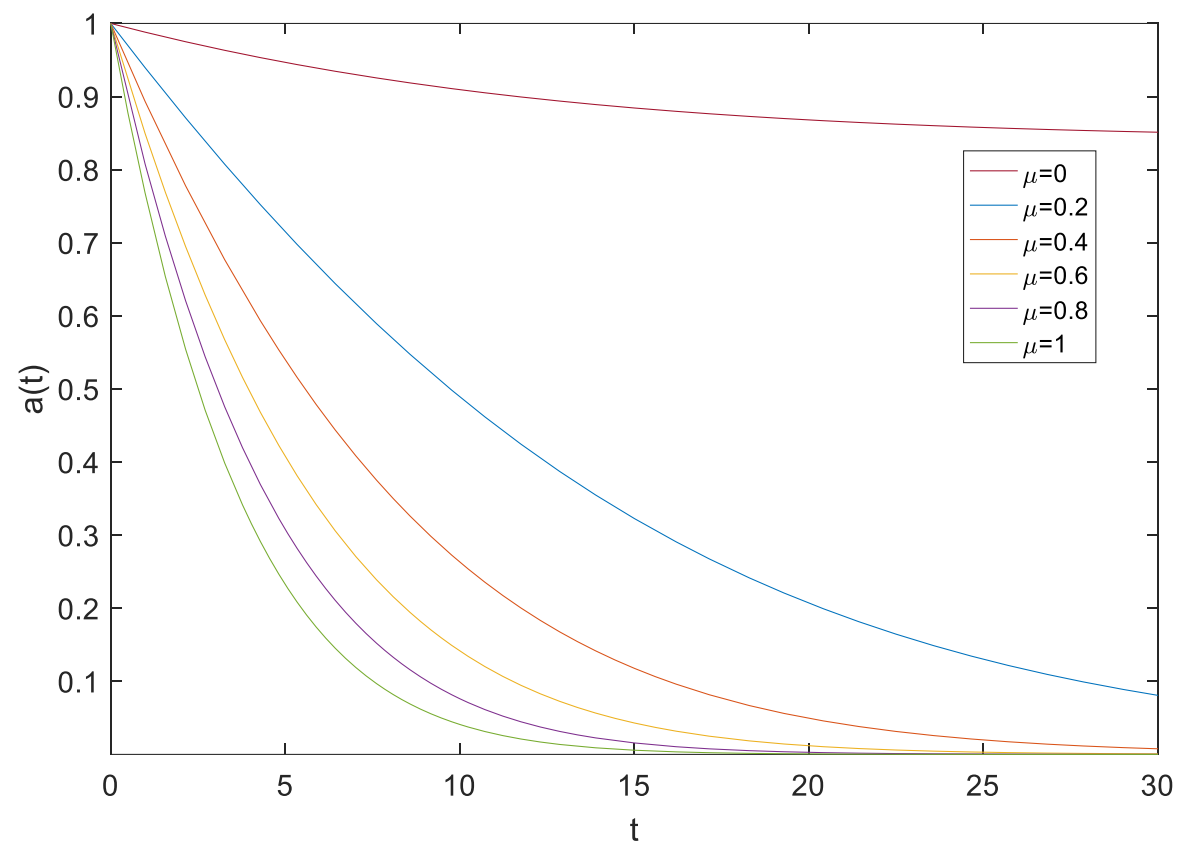

Şekil 3. Zamanla azalan kütleye sahip kütle yay sönüm sisteminin deplasman genliği-zaman grafiği $\left(h_{2}=0, \omega_{0}=10, m_{r}=1, \varepsilon=0.1\right)$

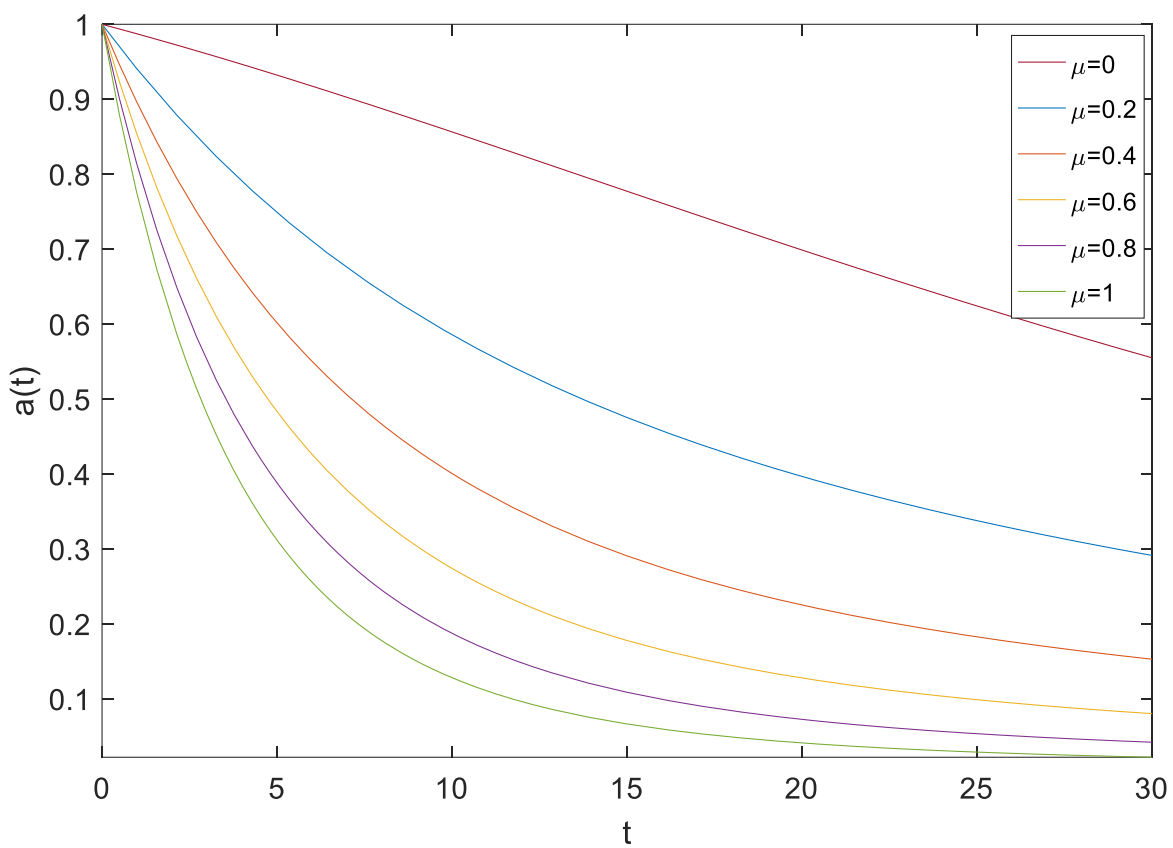

Şekil 4. Zamanla artan kütleye sahip kütle yay sönüm sisteminin deplasman genliği-zaman grafiği $\left(h_{2} \neq 0, \omega_{0}=10, m_{r}=1, \varepsilon=0.1\right)$ 


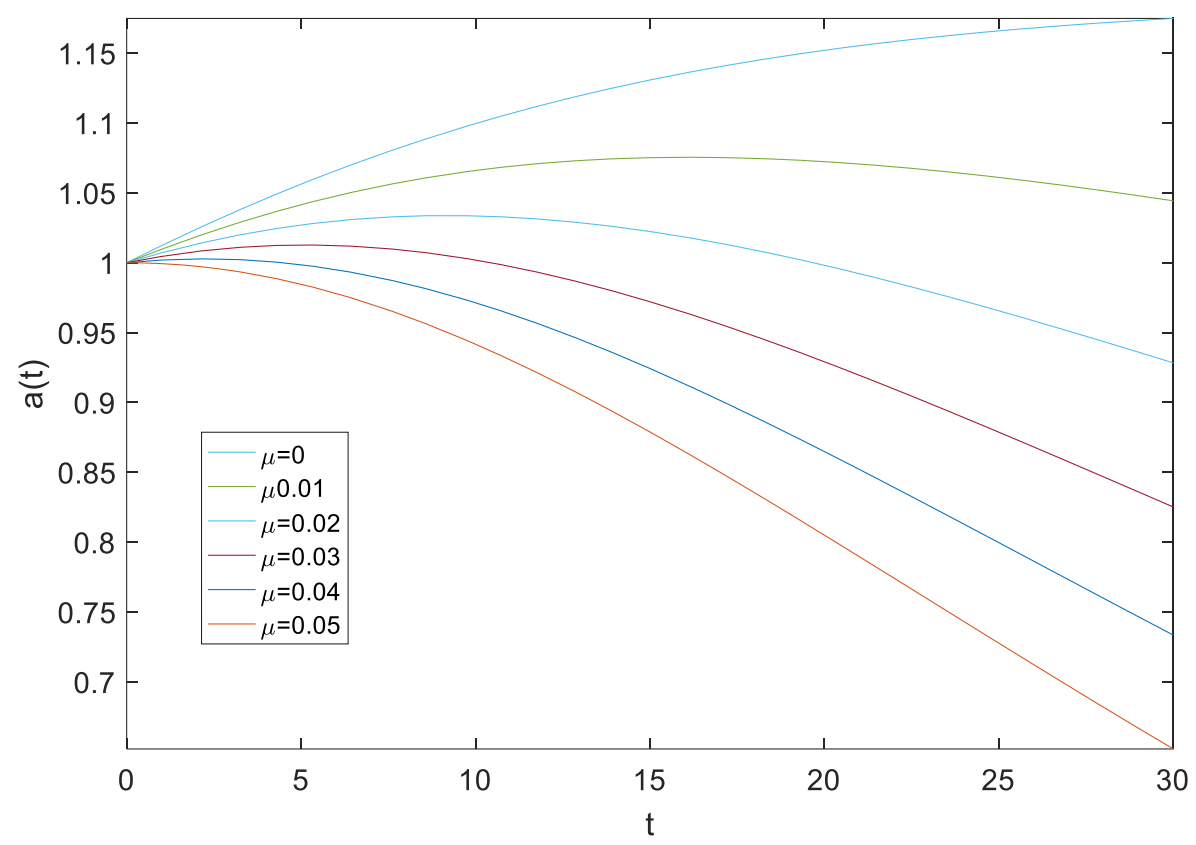

Şekil 5. Zamanla azalan kütleye sahip kütle yay sönüm sisteminin deplasman genliği-zaman grafiği $\left(h_{2} \neq 0, \omega_{0}=10, m_{r}=1, \varepsilon=0.1\right)$

Tablo 2. Zamanla değişen deplasman genliği değerleri $\left(\omega_{0}=10, m_{r}=1, \varepsilon=0.1, \mu=0\right)$

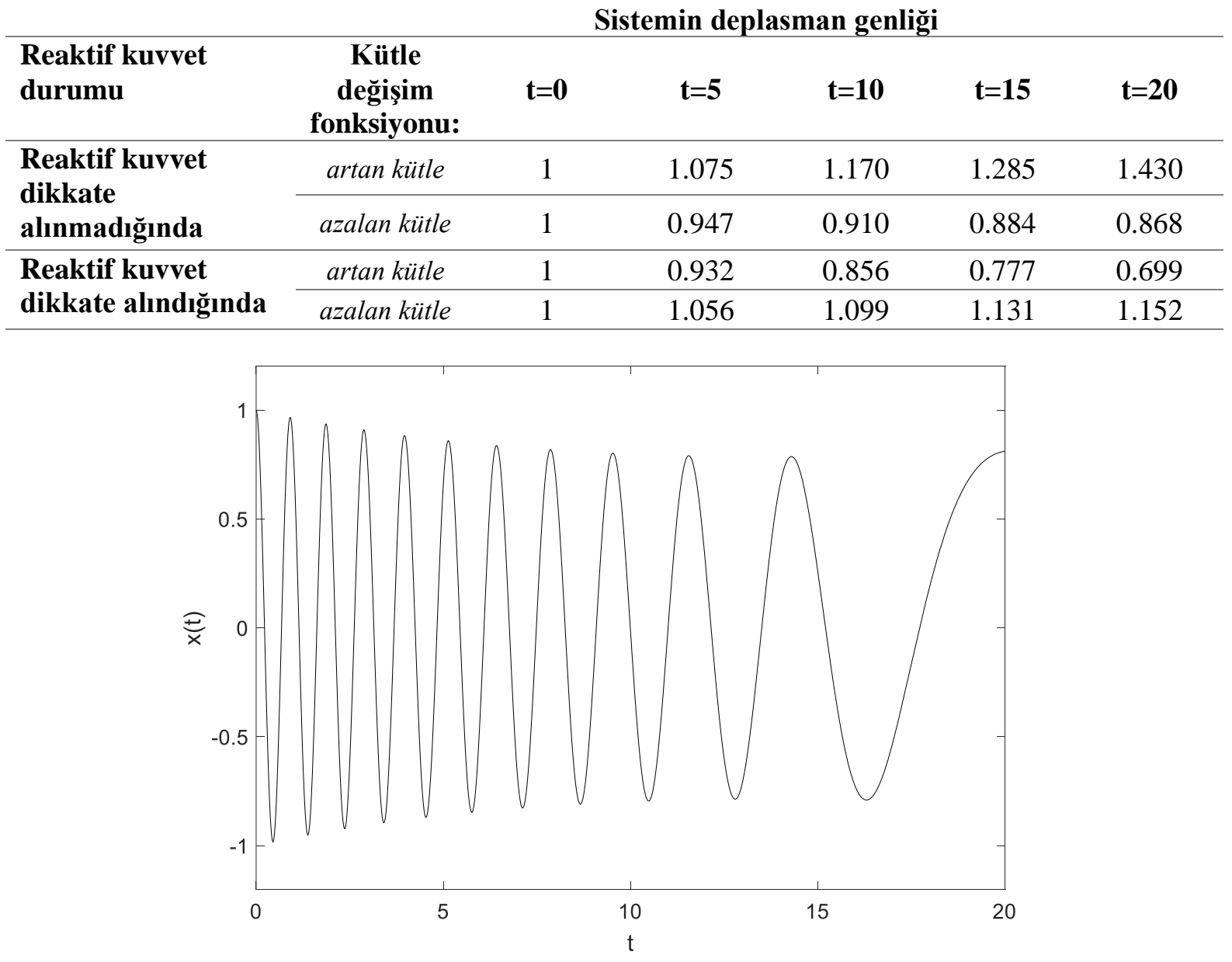

Şekil 6. Zamanla artan kütleye sahip kütle yay sönüm sisteminin deplasman-zaman grafiği $\left(\mathrm{h}_{2}=0, \omega_{0}=10, \mathrm{~m}_{\mathrm{r}}=1, \varepsilon=0.1, \mu=0.2\right)$ 


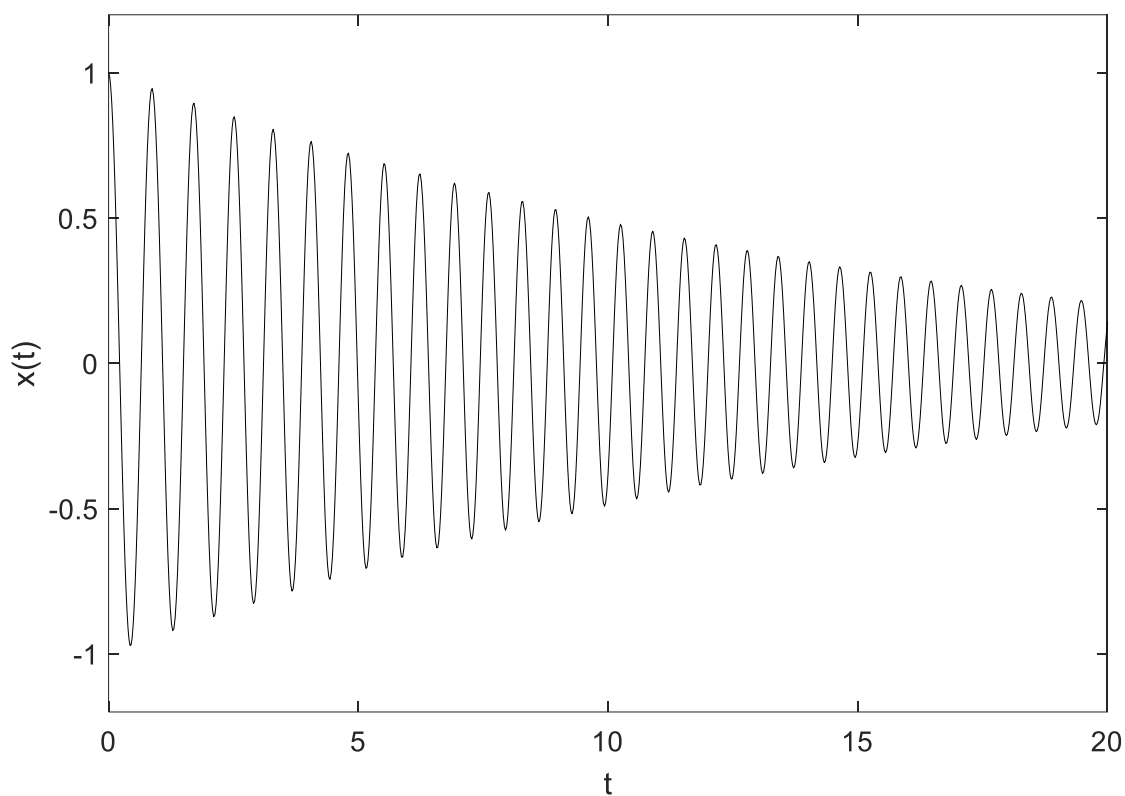

Şekil 7. Zamanla azalan kütleye sahip kütle yay sönüm sisteminin deplasman-zaman grafiği $\left(h_{2}=0, \omega_{0}=10, m_{r}=1, \varepsilon=0.1, \mu=0.2\right)$

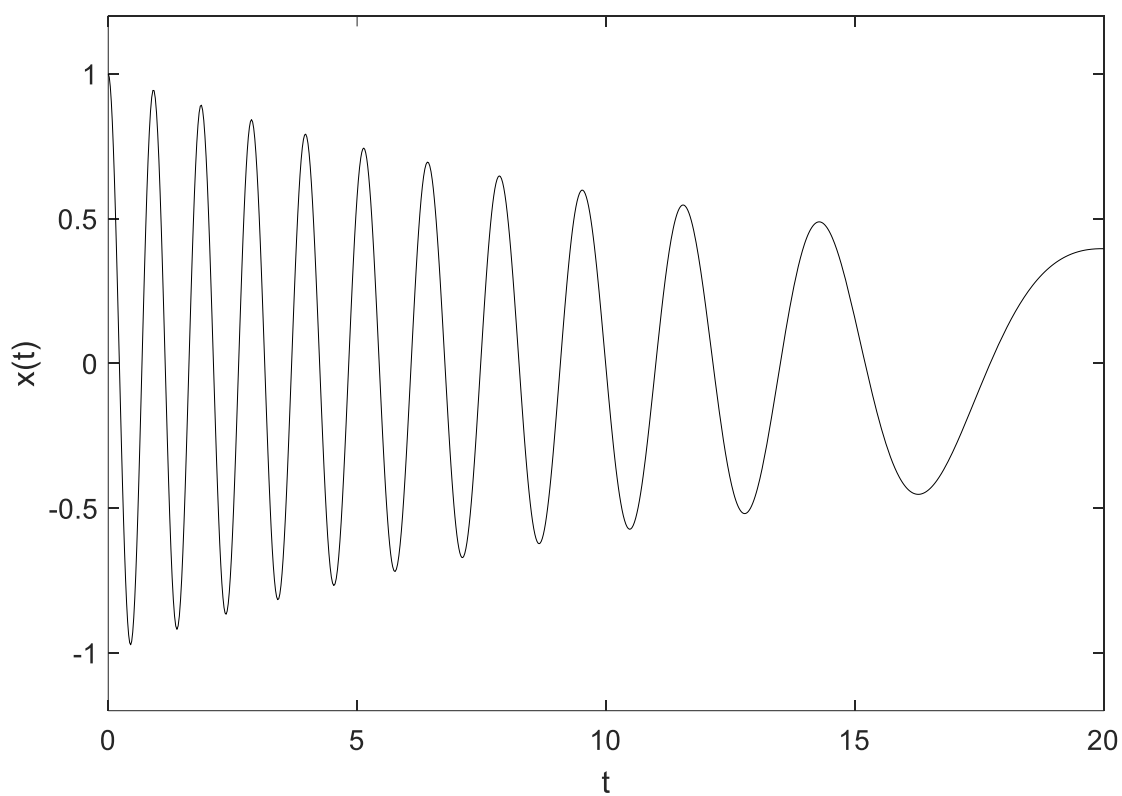

Şekil 8. Zamanla artan kütleye sahip kütle yay sönüm sisteminin deplasman-zaman grafiği $\left(h_{2} \neq 0, \omega_{0}=10, m_{r}=1, \varepsilon=0.1, \mu=0.2\right)$ 


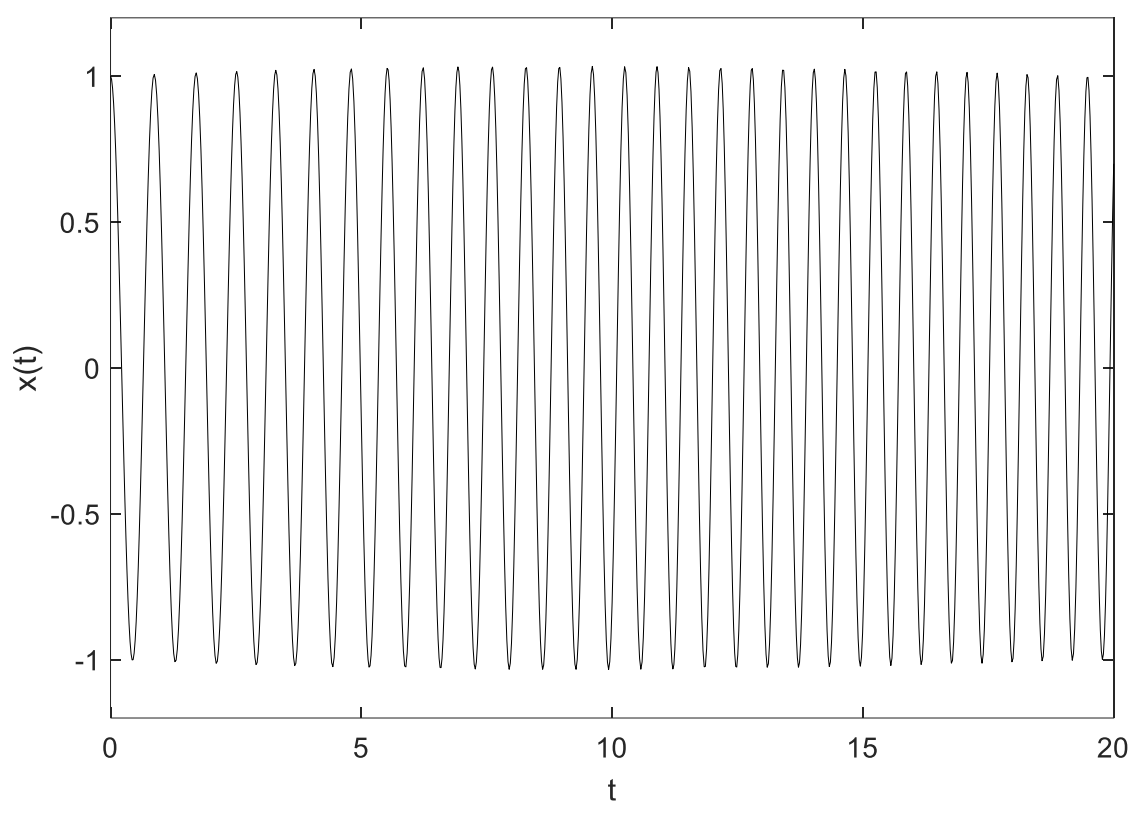

Şekil 9. Zamanla azalan kütleye sahip kütle yay sönüm sisteminin deplasman-zaman grafiği $\left(h_{2} \neq 0, \omega_{0}=10, m_{r}=1, \varepsilon=0.1, \mu=0.02\right)$

\section{IV.SONUC}

Bu çalışmada zamana bağlı yavaşça değişen kütleye sahip bir osilatörün boyutsuz haldeki denklemi çok ölçekli metot ile çözülmüştür. Elde edilen çözümlerde sistemin genliği ve frekansı zamanla değişmektedir. Kütle değişim hızından kaynaklanan reaktif kuvvetin, genlik değişimi üzerinde direkt etkisi vardır. Sisteme sönüm dâhil edildiğinde sönüm kuvveti ve reaktif kuvvet birbirini dengelemektedir. Çalışmada, reaktif kuvvet dikkate alındığında veya alınmadığında farklı sönüm değerleri için sistemin genlik ve frekans davranışları sunulmaktadır. Sönüm kuvveti her durum için genliği azaltmaktadır. Sistemin kütlesindeki artma frekansı her durum için arttırmaktayken, kütlenin azalması her durum için frekansı azaltmaktadır. Reaktif kuvvet, zamanla artan kütleli sistem için genlikleri azaltmakta, zamanla azalan kütleli sistem için genlikleri arttırmaktadır. Sonuç olarak bu çalışmada fiziksel olarak birçok karşılığı olan kütlesi üstel olarak değişken kütleli sönümlü sistemlerin davranışlarını veren çözümler elde edilmiş ve grafiklerle sunulmuştur.

\section{KAYNAKLAR}

[1] L. Cveticanin, Dynamics of Bodies with Time-Variable Mass. Mathematical and Analytical Techniques with Applications to Engineering, Switzerland: Springer, 2016.

[2] H. Saruhan, M. Kam, F. Kara, "Dynamic behavior analysis of rotor supported by damped rolling element bearing housing," Journal of Polytechnic, vol. 20, no.1, pp. 159-164, 2017.

[3] N. Alçelik, M. Kam, "Dönen makinelerde eksenel kaçıklık ve dengesizliğin titreşim analizi vibration analysis of axis misalignment and unbalance in rotating machineries," BSEU Journal of Science, vol. 7, pp. 256-269, 2020.

[4] A. K. Abramian, W. T. Van Horssen, S. A. Vakulenko, "On oscillations of a beam with a small rigidity and a time-varying mass," Nonlinear Dynamics, vol. 78, pp. 449-459, 2014. 
[5] L. Cveticanin "Approximate solution of a time-dependent differential equation," Meccanica, vol. 30, pp. 665-671, 1995.

[6] Y. Terumichi, M. Ohtsyka, M. Yoshizawa, Y. Fukawa, Y. Tsujioka "Nonstationary vibrations of a string with time-varying length and a mass-spring system attached at the lower end," Nonlineer Dynamics, vol. 12, pp.3 9-55, 1997.

[7] L. Cveticanin "Self-excited vibrations of the variable mass rotor/fluid system," Journal of Sound and Vibration, vol. 212, no. 4, pp. 685-702,1998.

[8] H.J. Holl, A.K. Belyaev, H. Irschik "Simulation of the duffing-oscillator with time-varying mass by a BEM in time," Computers and Structures, vol. 73, pp. 177-186, 1999.

[9] J. Flores, G. Solovey, S. Gil "Variable mass oscillator," American Association of Physics Teachers, vol. 71, no. 7, pp. 721-725, 2003.

[10] A.H.P. Van der Burgh, Hartono, A.K.Abramian, "A new model for the study of the rain-windinduced vibrations of a simple oscillator," International Journal of Non-Linear Mechanics, vol. 41, pp. $345-358,2016$.

[11] W.T. Horssen Van, O.V. Pischanskyy, "On the stability properties of a damped oscillator with a periodically time-varying mass," Journal of Sound and Vibration, vol. 330, pp. 3257-3269, 2011.

[12] Y. Zhu, S. Wang, "Analyzing the vibration system with time-varying mass," Applied Mechanics and Materials, vol. 50-51, pp. 160-165, 2011.

[13] M. Zukovic, I. Kovacic "An insight into the behaviour of the oscillators with a periodically piecewise-defined time-varying mass," Communications in Nonlinear Science and Numerical Simulation, vol. 42, pp. 187-203, 2017.

[14] W.T. Van Horssen, O.V. Pischanskyy, J.L.A. Dubbeldam, "On the forced vibrations of an oscillator with a periodically time-varying mass", Journal of Sound and Vibration, vol. 329, pp. 721-732, 2010.

[15] B. Ji-hu, Z. Peng, Z. Chang-ming, "Modeling of rope longitudinal vibration on flexible hoisting system with time-varying length," Applied Mechanics and Materials, vol. 130-134, pp. 2783-2788, 2012.

[16] W.T. Van Horssen, A.K. Abramian, Hartono, "On the free vibrations of an oscillator with a periodically time-varying mass," Journal of Sound and Vibration, vol. 298, pp. 1166-1172, 2006.

[17] O.V. Pischanskyy, W.T. Van Horssen, "On the nonlinear dynamics of a single degree of freedom oscillator with a time-varying mass," Journal of Sound and Vibration, vol. 331, pp. 1887-1897, 2012.

[18] H. Irschik, H. J. Holl, "Mechanics of variable-mass systems-part 1: Balance of mass and linear momentum," American Society of Mechanical Engineers, vol. 57, no. 2, pp. 145-160.

[19] A.H. Nayfeh, Introduction to Perturbation Techniques, New York, USA: John Wiley \& Sons, 1981.

[20] A.H. Nayfeh, J.F. Nayfeh, D.T. Mook, Nonlinear Oscillations, New York, USA: John Wiley \& Sons, 1995.

[21] A.H. Nayfeh, Perturbation Methods, A. Wiley Interscience, New York, USA: John Wiley \& Sons, 1973. 